\title{
Research on the Mode of Cultivating Football Reserve Talents \\ Based on University
}

\author{
Weiping Xie \\ Pingxiang University, Pingxiang, Jiangxi, 337055, China
}

Keywords: university pivot; football reserve talents; training model

\begin{abstract}
The purpose of this research is to establish a scientific and reasonable training model of football reserve talents based on university which is as the main body. The university as the hub and the professional club as the basis explore the feasibility of incorporating the training of competitive football reserve talents into the school education track. This model for the development of China's football industry to bring positive significance is expected.
\end{abstract}

\section{Introduction}

Modern football is one of the earliest sports programs which are carried out by colleges and universities in China [1-3]. Cultivating football talents in Chinese universities has a long history. According to historical records, as early as 1901, China's Shanghai St. John's University and Nanyang University has set up a football team [4]. The two schools played a match once a year since 1902. From 1923 to 1937, located in the mainland of West China University, Sichuan University have also set up a football team. Shanghai Jiaotong University football team also visited New Zealand, Japan and other countries to compete $[5,6]$. The establishment of these school teams and activities for the development of old Chinese football played a significant role in promoting football career [7].

Many scholars have studied and discussed the mode of cultivating football reserve talents in China [8]. It is believed that relying on the main line of school, strengthening the cooperation between sports and education departments to build up a train model of football athletes through "university - middle school - primary school". The Football association changed its functions, and from the previous "do" to "management" change the focus of the work more biased in favor of the development of youth football. The establishment of soccer players in harmony with the physical and mental development of scientific football reserve personnel training approach is needed.

\section{Research purposes}

Football reserve talents are the basis of the development of a national football. The world's football power are strategic vision, and take different ways to cultivate reserve talents. It is an important guarantee to expand the football population, improve the level of football, and promote the sustainable, stable and healthy development of 
soccer. Since 1994, China's professional football league has brought new vitality but at the same time it should be clear to see that the current level of China's football does not achieve "quality" breakthrough. This study attempts to build a university as a hub for the cultivation of football talent model analysis, and to achieve the following research objectives:

(1) Understand the status of the current football reserve talents training mode and the development of football in primary and middle schools, and explore the causes of the existing problems.

(2) Analyze the existing problems in the training mode of the "reserve-sports-education" model for Chinese soccer reserve talents, and summarize the characteristics, advantages and disadvantages of this training mode.

(3) Try to explore a scientific and reasonable way of football reserve personnel training, and gradually improve the "combination of sports and education" model for our football reserve personnel training to provide a new path.

\section{Research methods}

\subsection{The design of the questionnaire}

According to the content and purpose of this study, and following the basic requirements of sociology on the design of the questionnaire, the author designed a new method for the design of the questionnaire, and made a thorough study on the subject, " Expert questionnaire "," coaches' questionnaire "and" athlete questionnaire ".

\subsection{The issuance and recovery of the questionnaire}

Table 1. Questionnaire issuance and recovery

\begin{tabular}{cccccc}
\hline & $\begin{array}{c}\text { Number of } \\
\text { distributed }\end{array}$ & $\begin{array}{c}\text { Number of } \\
\text { returned }\end{array}$ & $\begin{array}{c}\text { Valid } \\
\text { questionnaire }\end{array}$ & $\begin{array}{c}\text { Recovery } \\
\text { rate }\end{array}$ & Efficient \\
\hline Expert questionnaire & 16 & 16 & 16 & $100 \%$ & $100 \%$ \\
Coach questionnaire & 13 & 12 & 12 & $100 \%$ & $100 \%$ \\
Athlete questionnaire & 140 & 138 & 131 & $98.6 \%$ & $93.6 \%$ \\
Total & 169 & 167 & 160 & $98.8 \%$ & $94.7 \%$ \\
\hline
\end{tabular}

The questionnaires were sent by email and sent to friends. The questionnaires were distributed to 15 experts, 14 coaches, and 140 questionnaires for athletes. 167 were recovered, and 160 valid questionnaires and the total recovery rate was $98.8 \%$. The effective recovery rate is $94.7 \%$ (see in Table 1 ).

\section{Research results and analysis}

\subsection{Introduction of the current football reserve personnel training mode}

China's traditional three - tier network training management system is: grass roots schools - amateur sports schools - provincial professional team of personnel training mode. This traditional system has long been used nationwide, and it is characterized by: personnel training in the form of linear training and selection system which is funded by the state. After coaches preferred, pure planning organization is used. In 1994, the former State Sports Commission of football as a breakthrough in 
sports, football as a pilot system reform, and the establishment of professional football club in China is established. The implementation of professional, football began to market and industrialization road. Football reserve personnel training also begins to a multi-polarization. This is manifested in: the proportion of government investment decreases from the past plan to train the system to market-oriented training system; in the youth football talent training approach, the football club echelon, private football schools and amateur clubs come into being, and enrich the youth football talent training channels. At present, the main ways of cultivating young talents in China are professional club echelon, football school, amateur club, amateur sports school and traditional project middle school.

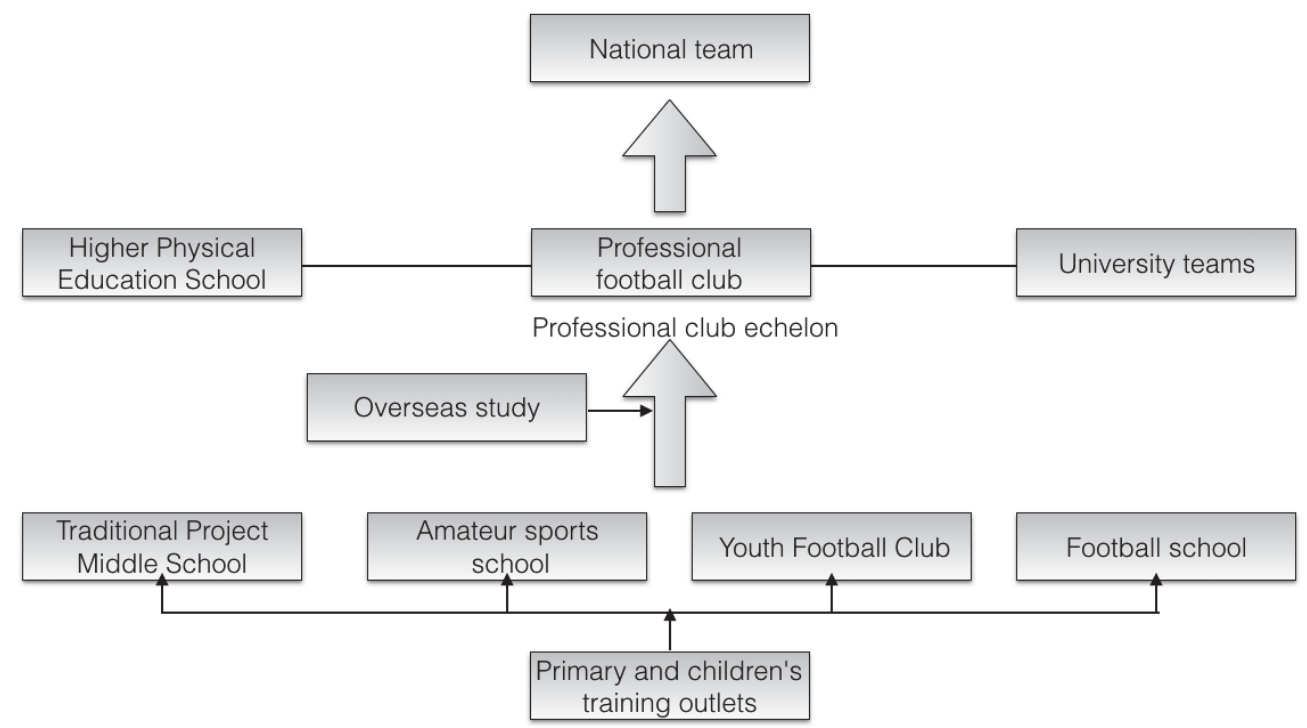

Figure 1. The main ways of cultivating our football reserve personnel

\subsection{A brief introduction to the present training mode of high - level gootball teams in colleges and universities}

\subsubsection{The level of the athletes}

In the surveyed schools, more than one of the football players is only 14 people to investigate the total number $10.7 \%$, of which there is no fitness level football player. In the present study, the reasons for the lack of high-level football players are as follows: first, in recent years, colleges and universities pay attention to the formation of high-level football teams, and competition for talent is increasing; secondly, the employment pressure of college graduates is increasing, and the level of athletes can not find a satisfactory job after graduation, so they tend to rely on the existing capacity as soon as possible to find their own social position. The results of a detailed survey of 131 student athletes from seven universities (Jiangsu University, Nanjing University of Technology, Henan University and Shanghai Institute of Physical Education) are shown in Table 6. 
Table 2. Athlete level situation

\begin{tabular}{ccc}
\hline & Number of people & Percentage \\
\hline Master class & 0 & $0 \%$ \\
Level one & 14 & $10.7 \%$ \\
Level two & 117 & $89.3 \%$ \\
Total & 131 & $100 \%$ \\
\hline
\end{tabular}

\subsubsection{Construct the reserve talent model of football in universities}

To build a "pyramid" type of football reserve personnel training mode, which is solid in foundation, smooth in transportation channel, reasonable in structure and closely connected with each level, is a strategic measure to keep the sustainable development of Chinese soccer competitive level. In this study, based on the existing football reserve personnel training system and the successful experience of developed countries, the paper puts forward a new type of football reserve talent training mode based on the school system as the main body, the university as the hub and the professional football club as the basis. Cultivate high-quality cultural, athletic level and the overall quality of the high-quality football reserve personnel. Promote the cause of China's football health, vigorous development as the ultimate goal.

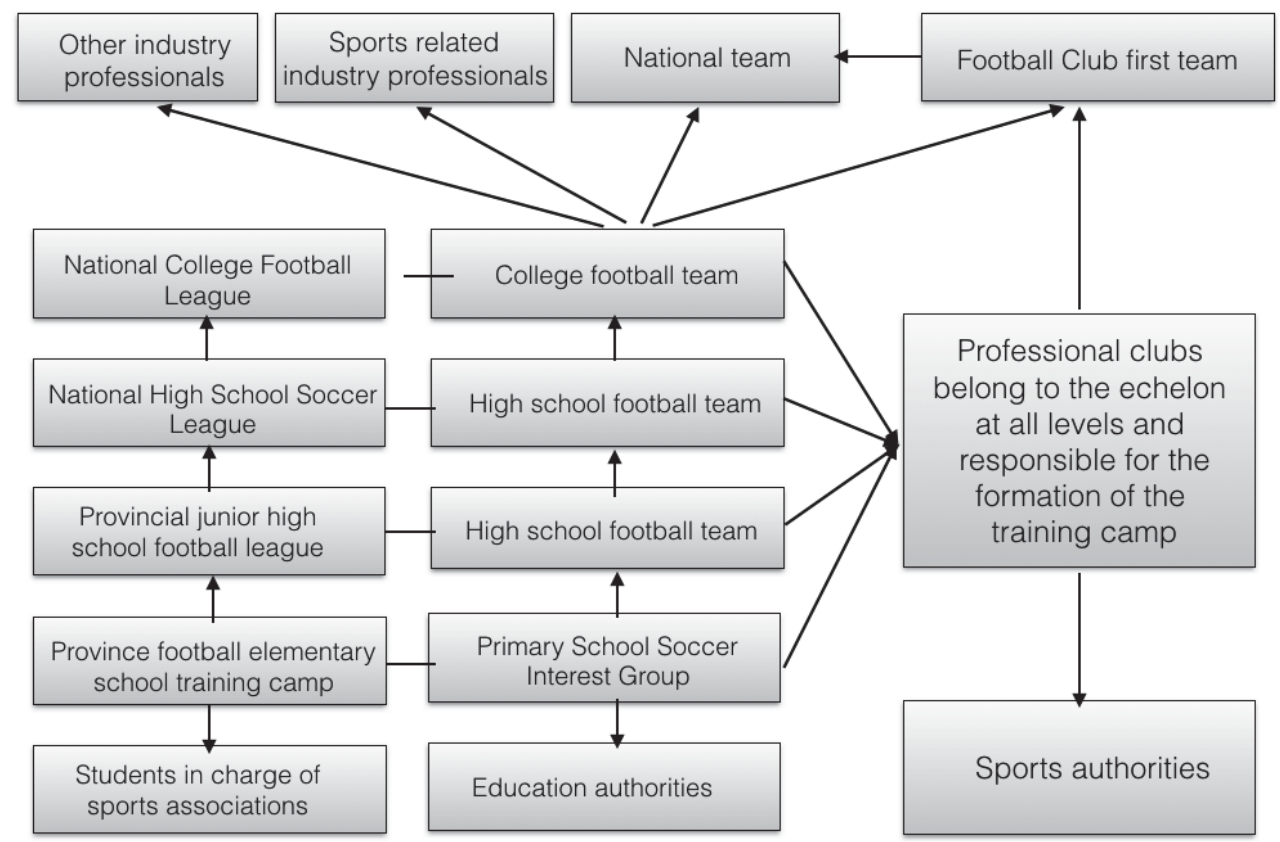

Figure 2. Cultivating soccer reserve talents model path with university as the hub

\subsubsection{The new model of innovation}

The current system of football reserve personnel training model is lack of systematic management and integrity of the structure, and it can not be effective to ensure the number and quality of the game. Competition is an effective way to test the training effect, and it is also a platform for athletes to display and improve their skills. It can effectively promote the progress of athletes and the running of sports teams. Therefore, the establishment and development of competition system must be attached importance in the training of football reserve talents. The new model which 
is established from the primary school football exchange training camps to the college students football league competition system, fully guarantee the athletes and sports teams to get exercise training and mutual learning exchange opportunities.

\section{Summary}

The new model of football reserve talents training based on the university is feasible, which can promote the comprehensive development of athletes, expand the talent base, provide the smooth channel of talent transmission, and accord with the development trend of football and modern society to the talented person of the demand. China's football reserve personnel training system development and improvement have a positive significance. The development of the new model requires the support of the government and the enthusiasm of all sectors of society to participate. In the course of deepening the system reform of high-level sports teams in colleges and universities, it is inseparable from the support of the government, the cooperation of social organizations, enterprises and institutions, to explore the new mode of cultivating football reserve talents with schools as the main body.

\section{References}

[1]. Wang R. Training and Reform Scheme of Football Talents in China[M]// Proceedings of the 2nd International Conference on Green Communications and Networks 2012 (GCN 2012): Volume 4. Springer Berlin Heidelberg, 2013:309-317.

[2]. Lang J, Wang C, Wang J, et al. Building the Mode of Training Football Talents in Chinese Schools[J]. Journal of Shenyang Sport University, 2014.

[3]. Kourunen. Research on Physical Training of Sports Reserve Talents of Group ball Games in Combination with Gymnastics[J]. Journal of Capital University of Physical Education \& Sports, 2016.

[4]. Brady C, Bolchover D, Sturgess B. Managing in the talent economy: the football model for business[J]. IEEE Engineering Management Review, 2012, 40(1):58-72.

[5]. Dong H Q. Youth football training philosophy and training of football reserve talents[J]. Journal of Jiamusi Education Institute, 2012.

[6]. Ren C. Talents Training Models of the World's Major Soccer Powers and Enlightenment[J]. Journal of Shenyang Sport University, 2011.

[7]. Shi L I, Xue-Jun. On Reserve Personnel Training System of Women Football Athletics in China[J]. Journal of Huizhou University, 2012.

[8]. Huffman L T, Cooper C G. I'm taking my talents to. an examination of hometown socio-economic status on the college-choice factors of football student-athletes at a southeastern university.[J]. Journal of Issues in Intercollegiate Athletics, 2012(5286):403. 